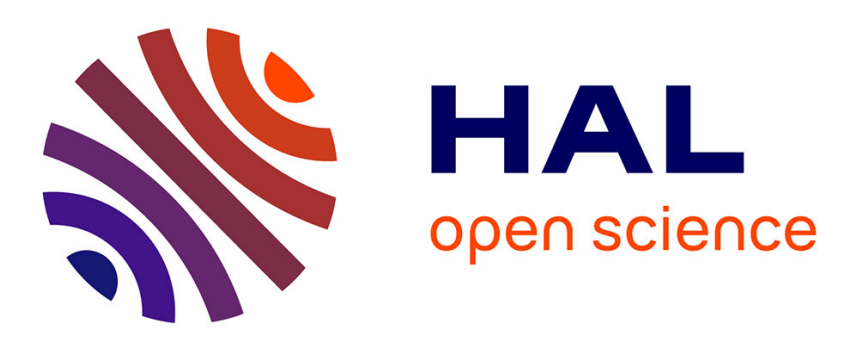

\title{
Effect of carbon nanotube hybrid on the microstructure and properties of AlN skeleton-reinforced highly oriented graphite flake composites
}

Xiaoyu Zhang, Yuanyuan Zhu, Wenqi Xie, Haoran Pang, Delong He, Kai He, Jinbo Bai, Zhongqi Shi

\section{To cite this version:}

Xiaoyu Zhang, Yuanyuan Zhu, Wenqi Xie, Haoran Pang, Delong He, et al.. Effect of carbon nanotube hybrid on the microstructure and properties of AlN skeleton-reinforced highly oriented graphite flake composites. Ceramics International, 2021, 10.1016/j.ceramint.2021.10.220 . hal-03414500

\author{
HAL Id: hal-03414500 \\ https://hal.science/hal-03414500
}

Submitted on 4 Nov 2021

HAL is a multi-disciplinary open access archive for the deposit and dissemination of scientific research documents, whether they are published or not. The documents may come from teaching and research institutions in France or abroad, or from public or private research centers.
L'archive ouverte pluridisciplinaire HAL, est destinée au dépôt et à la diffusion de documents scientifiques de niveau recherche, publiés ou non, émanant des établissements d'enseignement et de recherche français ou étrangers, des laboratoires publics ou privés. 


\title{
Effect of carbon nanotube hybrid on the microstructure and properties of AIN
}

skeleton-reinforced highly oriented graphite flake composites

Xiaoyu Zhang ${ }^{1}$, Yuanyuan Zhu' ${ }^{1}$, Wenqi Xie ${ }^{1}$, Haoran Pang ${ }^{1}$, Delong $\mathrm{He}^{2,{ }^{*}}, \mathrm{Kai} \mathrm{He}^{3}$, Jinbo Bai ${ }^{2}$, Zhongqi $\mathrm{Shi}^{1{ }^{1 *}}$

${ }^{1}$ State Key Laboratory for Mechanical Behavior of Materials, Xi'an Jiaotong University, Xi'an 710049, China

${ }^{2}$ Université Paris-Saclay, CentraleSupélec, CNRS, Laboratoire Mécanique des Sols, Structures et Matériaux, 91190, Gif-sur-Yvette, France

${ }^{3}$ China Nuclear Power Engineering Co. Ltd., Beijing 100840, China

* Corresponding author. Tel: +86 29 82668610; Fax: +86 2982663453.

E-mail: delong.he@centralesupelec.fr; zhongqishi@mail.xjtu.edu.cn (Z Shi)

\begin{abstract}
AlN skeleton structure-reinforced highly oriented graphite flake (AlN/GF) composites have become a promising candidate for thermal management materials owing to their high thermal conductivity and low thermal expansion. However, the applications of AIN/GF composites are still limited by their poor mechanical properties. Herein, a carbon nanotube-coated alumina $\left(\mathrm{Al}_{2} \mathrm{O}_{3} @ \mathrm{CNT}\right)$ hybrid was used as a reinforcement to improve the mechanical performance of AlN/GF composites prepared via vacuum infiltration followed by spark plasma sintering. It was found that the relative density and orientation degree of the composites decreased slightly with an increase in the $\mathrm{Al}_{2} \mathrm{O}_{3} @ \mathrm{CNT}$ content from 0 to $2 \mathrm{wt} \%$. However, the fracture toughness and bending strength of the composites improved significantly after the introduction of the $\mathrm{Al}_{2} \mathrm{O}_{3} @ \mathrm{CNT}$ hybrid reaching up to $1.66 \mathrm{MPa} \cdot \mathrm{m}^{1 / 2}$ and $95 \mathrm{MPa}$, respectively, which
\end{abstract}


correspond to an improvement of approximately $50 \%$ and $20 \%$ over those of the AlN/GF composite. With the addition of the $\mathrm{Al}_{2} \mathrm{O}_{3} @ \mathrm{CNTs}$, the thermal expansion of the composites increased from $7.3 \times 10^{-6} / \mathrm{K}$ to $\sim 15.5 \times 10^{-6} / \mathrm{K}$, while the thermal conductivity decreased from 442 to $\sim 253 \mathrm{~W} / \mathrm{m} / \mathrm{K}$. The toughening and strengthening mechanisms as well as the thermal impact mechanism of the composites were also investigated.

Keywords: Fracture behavior; carbon nanotubes; ceramics; composites

\section{Introduction}

The increasing power density and decreasing size of electric devices have made their thermal management challenging [1-3]. To efficiently dissipate the heat of electronic components, advanced thermal management materials (TMMs) with excellent thermal conductivity $(\mathrm{TC}, \geq 250 \mathrm{~W} / \mathrm{m} / \mathrm{K})$ and low density should be developed. In addition, an ideal TMM should also possess good mechanical properties, such as high fracture toughness and high bending strength, for application in electronic devices $[4,5]$. In this regard, highly oriented graphite (HOG) has been widely investigated because of its light weight $\left(2.2 \mathrm{~g} / \mathrm{cm}^{3}\right)$ and high in-plane TC $(\sim 500$ $\mathrm{W} / \mathrm{m} / \mathrm{K})$. [6,7]. However, poor bending strength $(<30 \mathrm{MPa})$ severely limits its application in advanced TMMs $[6,8,9]$.

To improve the mechanical properties of HOG, tough metals and strong ceramics, such as $\mathrm{Cu}$ and aluminum nitride (AIN) are introduced into the graphite matrix as reinforcements [10-12]. Nevertheless, the high density of $\mathrm{Cu} /$ graphite composites increases the weight of electronic devices, which is not desired. In our previous study 
[13], the introduction of a three-dimensional (3D) continuous AlN skeleton structure in highly oriented graphite flakes (AlN/GF) could increase the bending strength of the graphite matrix to $\sim 80 \mathrm{MPa}$ while maintaining high TC and low density. Unfortunately, the overall mechanical properties of the AlN/GF hybrid could not fulfill the requirements of advanced TMMs. Thus, both the strength and toughness of AlN/GF composites should be improved further to realize their TMM applications.

Recently, it has been reported that the introduction of one-dimensional carbon nanofillers (such as nanotubes, nanofibers, and nanorods) into the interlayer of $\mathrm{HOG}$ can significantly improve its mechanical properties $[14,15]$. Among these carbon nanofillers, carbon nanotubes (CNTs) with exceptional tensile strength (20-100 GPa) are considered as an ideal reinforcement for HOG [16-18]. Liu et al. [19] prepared HOG by hot-pressing GF with the CNTs grown on its surface. The bending strength of the HOG reached as high as $46 \mathrm{MPa}$, which is $52 \%$ higher than that of the GF. However, most studies on the strengthening and toughening of HOG by CNTs have not attained the values predicted by theory, presumably because of the poor dispersion of CNTs in the HOG matrix [19]. It has been reported that the in situ growth of CNTs on the surface of micrometric substrates is an efficient method to disperse CNTs [20]. In our previous study, we grew CNTs vertically on the surface of $\mathrm{Al}_{2} \mathrm{O}_{3}$ particles $\left(\mathrm{Al}_{2} \mathrm{O}_{3} @ \mathrm{CNTs}\right)$ by chemical vapor deposition (CVD) [21]. The as-prepared "urchinlike" structure showed good CNT dispersion. The mechanical properties of polymer based composite were effectively improved by only a small amount of such $\mathrm{Al}_{2} \mathrm{O}_{3} @ \mathrm{CNT}$ hybrid $[21,22]$. In addition, the CNT orientation significantly affects the 
properties of the composites [23]. The alignment of CNTs largely contributes to the improvement in the mechanical properties of HOG [24]. For instance, Wang et al. showed that the bending strength of HOG can be increased to $76 \mathrm{MPa}$ by intercalating aligned CNTs [25]. These results suggest that the introduction of $\mathrm{Al}_{2} \mathrm{O}_{3} @ \mathrm{CNT}$ hybrid powders with high alignment might be a promising strategy to enhance the mechanical properties of AlN/GF composites while maintaining high TC.

In this study, we prepared aligned $\mathrm{Al}_{2} \mathrm{O}_{3} @$ CNTs-reinforced AlN/GF composites (CNTs-AlN/GF) by combining the vacuum infiltration and spark plasma sintering (SPS) techniques. Vacuum infiltration facilitates the orientation of CNTs along the inplane direction of GF by the flow-directed force [26,27], which is necessary to improve the strength and toughness of the resulting composite. SPS has been widely used to rapidly sinter CNTs-reinforced composites at low temperatures to retain the CNT nanostructure and further orient the CNTs $[28,29]$. The effect of the $\mathrm{Al}_{2} \mathrm{O}_{3} @ \mathrm{CNT}$ concentration on the phase distribution, mechanical properties, and thermophysical properties of the CNTs-AlN/GF composites was investigated. The toughening and strengthening mechanisms of the CNT hybrid-reinforced composites were also elucidated.

\section{Experimental}

\subsection{Sample fabrication}

spherical AlN powder (99.9\% purity, $0.5 \mu \mathrm{m}$ in diameter, Tokuyama, Japan) and GF powder $(99.8 \%$ purity, diameter of $\sim 15 \mu \mathrm{m}$, thickness of $\sim 1 \mu \mathrm{m}$, Alfa Aesar, America) were used as the raw materials. Yttrium oxide $\left(\mathrm{Y}_{2} \mathrm{O}_{3}\right)$ powder $(5 \mathrm{wt} \%)(99.99 \%$ 
purity, Shanghai Yuelong, China) was added as the sintering aid. The $\mathrm{Al}_{2} \mathrm{O}_{3} @ \mathrm{CNT}$ hybrid powder was prepared using the CVD method [21]. First, $\alpha-\mathrm{Al}_{2} \mathrm{O}_{3}$ powder $(99.8 \%$ purity, Sumitomo Chemical Co. Ltd, Japan) was dispersed on the surface of a silica plate substrate. A ferrocene and xylene mixture solution $(0.05 \mathrm{mg} / \mathrm{mL})$ was injected into the reactor at $1025 \mathrm{~K}$ for $10 \mathrm{~min}$. CNTs grew in situ homogenously and self-organized on the surface of the micro-sized $\mathrm{Al}_{2} \mathrm{O}_{3}$ particles. Subsequently, "urchin-like" $\mathrm{Al}_{2} \mathrm{O}_{3} @ \mathrm{CNTs}$ hybrid powders were obtained. The details of the fabrication process for the hybrid powders are provided in our previous report [21]. Figure 1 shows the morphology and thermogravimetric analysis results of the as-synthesized $\mathrm{Al}_{2} \mathrm{O}_{3} @ \mathrm{CNT}$ hybrid powders. The average diameter of the CNTs was $\sim 50 \mathrm{~nm}$, and the thermogravimetric results showed that the average weight percent of CNTs on one $\mathrm{Al}_{2} \mathrm{O}_{3}$ particle was $\sim 55 \%$.
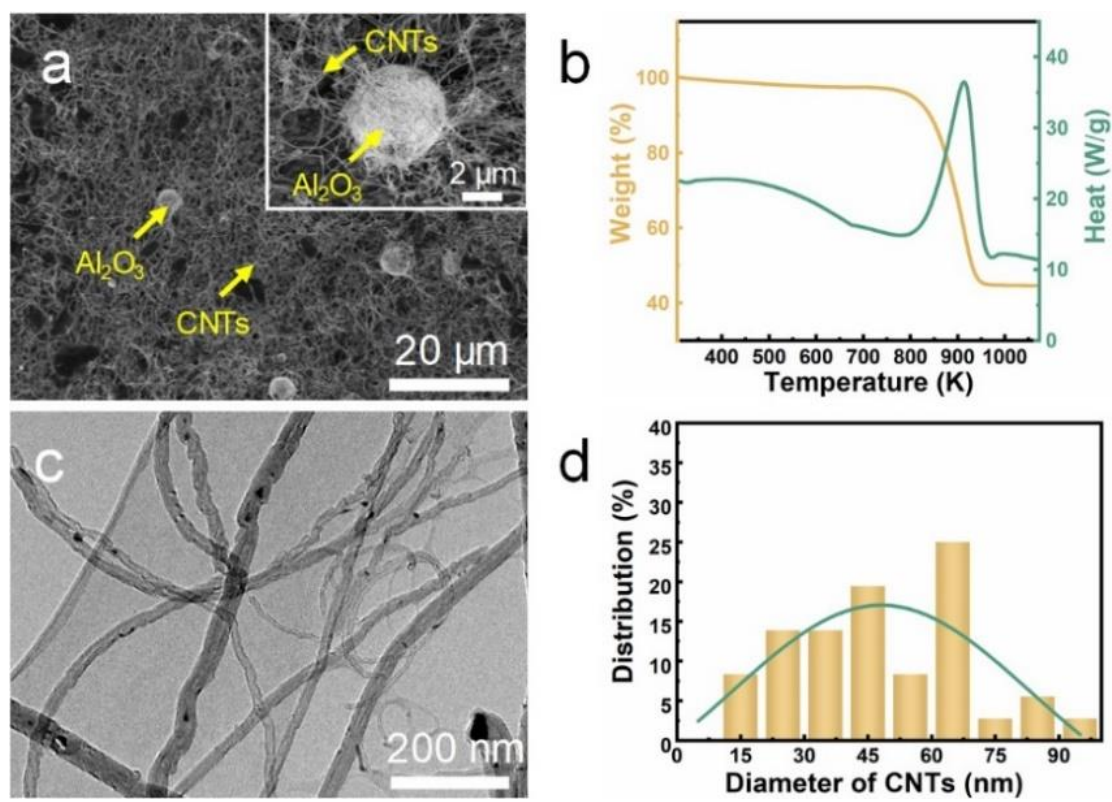

Figure 1 (a) SEM image, (b) thermogravimetric analyses and (c) TEM image of CNTs in $\mathrm{Al}_{2} \mathrm{O}_{3} @$ CNTs hybrid; (d) diameter distribution of CNTs. 
The CNTs-AlN/GF composites were fabricated by combing vacuum filtration with SPS, as shown in Figure 2. First, all the powders were weighed and ball-milled for $5 \mathrm{~h}$ using ethanol as the mixing media to obtain a slurry. The AlN:GF: $\mathrm{Y}_{2} \mathrm{O}_{3}$ weight ratio for all the samples was 20:80:5. A wet green body was then obtained via the vacuum filtration of the slurry. After removing the residual ethanol at $335 \mathrm{~K}$ for $24 \mathrm{~h}$, the asprepared green body was sintered at $1925 \mathrm{~K}$ for 5 min under $50 \mathrm{MPa}$ using an SPS apparatus (Ed-PASIII, Elenix Ltd, Japan). The $\mathrm{Al}_{2} \mathrm{O}_{3} @$ CNT content in the raw materials was varied $(0,0.5,1$, and $2 \mathrm{wt} \%)$. The composites obtained with $0,0.5,1$, and 2 wt $\% \mathrm{Al}_{2} \mathrm{O}_{3} @ \mathrm{CNTs}$ were labeled as AlN/GF, 0.5CNTs-AlN/GF, 1CNTs-AlN/GF, and 2CNTs-AlN/GF, respectively. The directions in the composites parallel and perpendicular to the SPS pressing axis were labeled as the z-axial and $x-y$ plane directions, respectively.
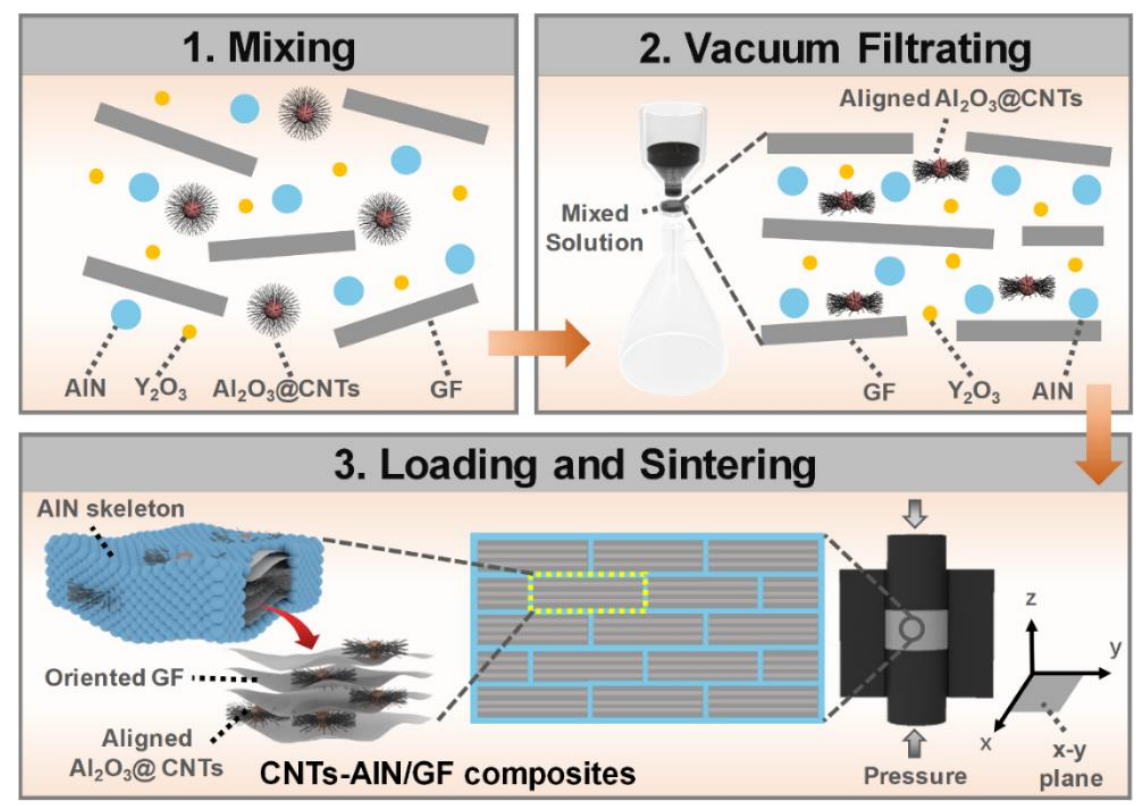

Figure 2 Schematic of the fabrication process for preparing the CNTs-AIN/GF composites. 


\subsection{Characterization}

The densities of the samples were obtained using the Archimedes immersion technique. The fractured morphologies of the composites in different directions were viewed using field-emission scanning electron microscopy (FESEM, SU6600, Hitachi, Japan). High-resolution transmission electron microscopy (HRTEM, JEM-2100F, Japan) was used to examine the microstructures of the CNTs. The X-ray diffraction (XRD) patterns of the specimens were recorded on an X-ray diffractometer (X-Pert Pro,

Netherlands) to analyze their phase compositions. The equation $f_{(00 l)}=\frac{P_{(00 l)}-P_{0}}{1-P_{0}}$ was used to calculate the orientation degree (Lotgering factor $f$ ) of the CNTs.

$$
\begin{gathered}
P_{(00 l)}=\frac{\sum I_{(00 l)}}{\sum I_{(h k l)}} \\
P_{0}=\frac{\sum I_{0(00 l)}}{\sum I_{0(h k l)}}
\end{gathered}
$$

where $\sum I_{(00 l)}$ and $\sum I_{(h k l)}$ are the integrated intensities of the $(00 l)$ XRD peaks and the summation of all the $(h k l)$ XRD peaks of graphite in the oriented composite patterns, respectively. Similarly, $\sum I_{0(00 l)}$ and $\sum I_{0(h k l)}$ are the summations of the $(00 l)$ XRD peaks and of all the $(h k l)$ peaks of graphite, respectively, in the composites with random orientation. The Raman spectra was performed using a Raman spectrometer (Nanofinder FLEXG, Tokyo Instruments Inc., Japan) with a 633-nm laser as the excitation light source.

The bending strengths of the sintered samples were determined using a three-point bending jig with a span of $16 \mathrm{~mm}$. The dimensions of the specimens for the bending strength tests were $3 \mathrm{~mm}$ by $4 \mathrm{~mm}$ by $16 \mathrm{~mm}$, and the loading rate was $0.5 \mathrm{~mm} / \mathrm{min}$. 
Fracture toughness values were measured using the single-edge notched beam method (specimen size: $16 \mathrm{~mm}$ by $4 \mathrm{~mm}$ by $2 \mathrm{~mm}$; span: $16 \mathrm{~mm}$; gap width and depth: $0.2 \mathrm{~mm}$ and $2 \mathrm{~mm}$, respectively; loading rate: $0.05 \mathrm{~mm} / \mathrm{min}$ ). The TC of the specimens (with dimensions of $\varnothing 12.7 \mathrm{~mm}$ by $2 \mathrm{~mm}$ for z-axial direction and $\varnothing 6 \mathrm{~mm}$ by $2 \mathrm{~mm}$ for $\mathrm{x}-\mathrm{y}$ plane) was measured using a laser-flash method (Netzsch LFA447 NanoFlash, Germany). The coefficients of thermal expansion (CTEs) of the specimens were determined using a horizontal dilatometer (DIL 402C, Netzsch, Germany) over the temperature range of $300-575 \mathrm{~K}$ with a heating rate of $5 \mathrm{~K} / \mathrm{min}$. The dimensions of the specimens for the CTE test were $5 \mathrm{~mm}$ by $5 \mathrm{~mm}$ by $5 \mathrm{~mm}$.

\section{Results and discussion}

\subsection{XRD characterization and density}

Figure $3 \mathrm{a}$ and $3 \mathrm{~b}$ show the XRD patterns of the 1CNTs-AIN/GF composite in the z-axial and $x-y$ plane directions, respectively. The diffraction peaks in the two directions displayed significant differences. The XRD pattern of the composite in the z-axial direction showed peaks at approximately $2 \theta=26.5$ and $54.7^{\circ}$ (Figure 3a). These can be attributed to (002) and (004) lattice planes of graphite. No other characteristic peaks of graphite were observed in this direction. However, five diffraction peaks corresponding to the (002), (100), (101), (004), and (110) planes of graphite were observed in the $x-y$ plane XRD pattern (Figure 3b). The differences in the XRD patterns in the two directions indicate that the composite possessed high anisotropy. In addition, the diffraction peaks of $\mathrm{AlN}, \mathrm{Y}_{2} \mathrm{O}_{3}$, and $\mathrm{Al}_{2} \mathrm{Y}_{4} \mathrm{O}_{9}$ were clearly observed in both the directions. The appearance of the $\mathrm{Al}_{2} \mathrm{Y}_{4} \mathrm{O}_{9}$ peak can be attributed to the reaction 
between $\mathrm{Y}_{2} \mathrm{O}_{3}$ and the $\mathrm{Al}_{2} \mathrm{O}_{3}$ originating from the $\mathrm{Al}_{2} \mathrm{O}_{3} @$ @NTs powder. $\mathrm{Al}_{2} \mathrm{Y}_{4} \mathrm{O}_{9}$ was formed as the eutectic compound and enhanced the sinterability of the resulting composite.
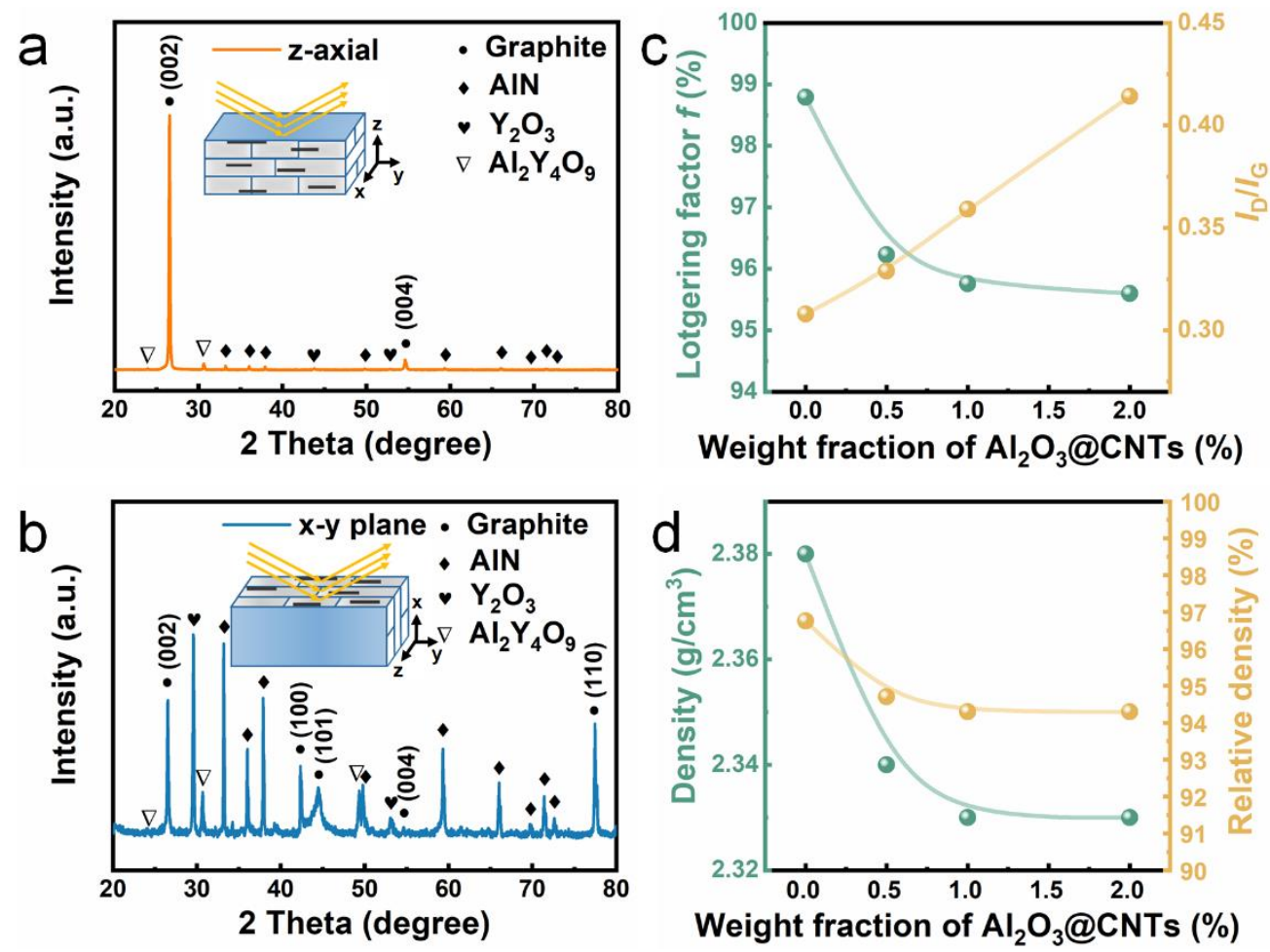

Figure 3 XRD patterns of 1CNTs-AIN/GF in (a) z-axial and (b) x-y plane directions;

(c) orientation degree, $I_{\mathrm{D}} / I_{\mathrm{G}}$, and (d) density and relative density of the CNTs-AlN/GF composites as a function of $\mathrm{Al}_{2} \mathrm{O}_{3} @ \mathrm{CNT}$ weight friction.

The orientation degree of the CNTs-AlN/GF composites is shown in Figure 3c. The value of the Lotgering factor $f$ lied between 0 and 1 . A higher value indicates a higher degree of orientation [30]. The orientation degrees of all the samples were higher than $95 \%$, which further demonstrates the good orientation of GF in the samples. However, the orientation degree decreased slightly with an increase in the $\mathrm{Al}_{2} \mathrm{O}_{3} @ \mathrm{CNT}$ weight fraction because the orientation of GF was disturbed by $\mathrm{Al}_{2} \mathrm{O}_{3} @ \mathrm{CNTs}$ during 
the vacuum filtration and SPS processes. The ratio of the intensity $\left(I_{\mathrm{D}} / I_{\mathrm{G}}\right)$ of the $\mathrm{D}$ peak (at $\sim 1328 \mathrm{~cm}^{-1}$ ) to that of the $\mathrm{G}$ peak (at $\sim 1587 \mathrm{~cm}^{-1}$ ) in the Raman spectra of the composites represented their GF crystalline quality. A lower $I_{\mathrm{D}} / I_{\mathrm{G}}$ ratio indicates a higher GF quality. The $I_{\mathrm{D}} / I_{\mathrm{G}}$ value of the composites increased gradually with an increase in the $\mathrm{Al}_{2} \mathrm{O}_{3} @ \mathrm{CNT}$ weight fraction (Figure 3c), indicating that the addition of $\mathrm{Al}_{2} \mathrm{O}_{3} @ \mathrm{CNTs}$ could cause the fracture, bending, and deformation of the GFs during the fabrication.
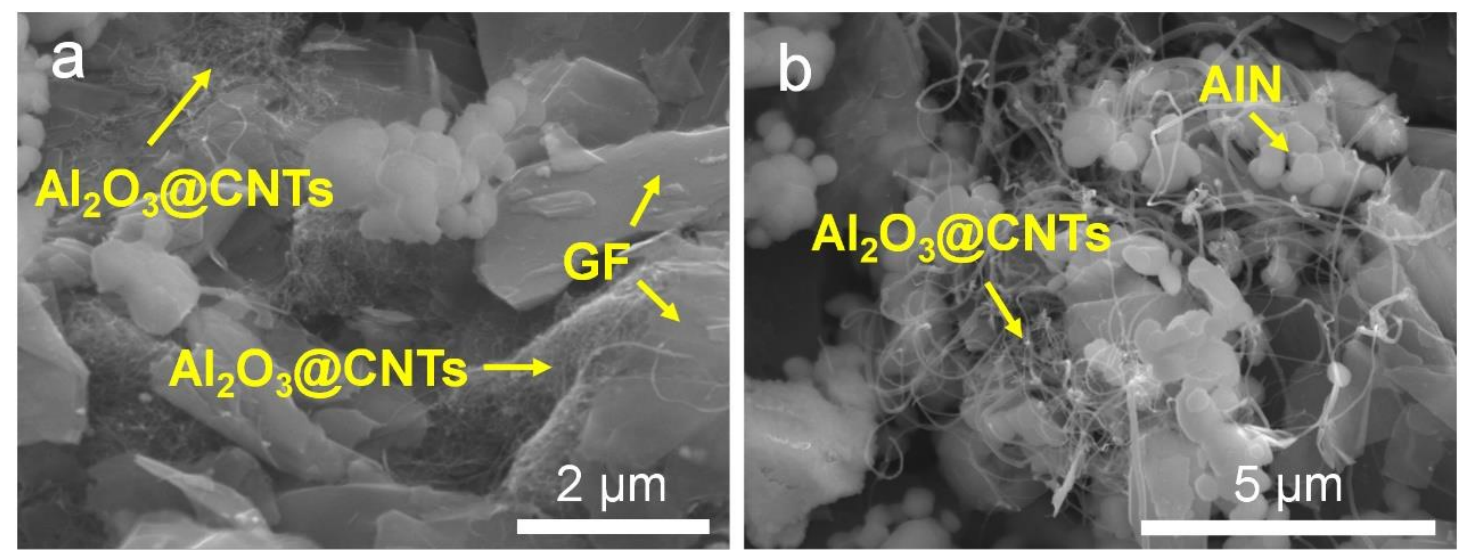

Figure 4 SEM images of mixed powders after ball-milling: (a) $\mathrm{Al}_{2} \mathrm{O}_{3} @$ CNTs adhered on the surface of GF and (b) $\mathrm{Al}_{2} \mathrm{O}_{3} @$ CNTs entangled with AlN particles.

Figure $3 \mathrm{~d}$ exhibits the density and relative density of the composites as functions of the $\mathrm{Al}_{2} \mathrm{O}_{3} @ \mathrm{CNT}$ weight fraction. Both the density and relative density of the composites decreased with an increase in the $\mathrm{Al}_{2} \mathrm{O}_{3} @ \mathrm{CNT}$ concentration, which indicates that the introduction of $\mathrm{Al}_{2} \mathrm{O}_{3} @ \mathrm{CNTs}$ had a certain retardation effect on the densification of the composites. It can be seen from the SEM images of the mixed powders subjected to ball milling (Figure 4a) that a large amount of $\mathrm{Al}_{2} \mathrm{O}_{3} @ \mathrm{CNTs}$ adhered onto the GF surface owing to the good chemical compatibility between the CNTs and GFs [31]. Although CNTs have relatively large aspect ratio, no significant 
entanglement of the CNTs adhered onto the GF surface was observed. This indicates that the CNTs were well-dispersed in the graphite matrix. However, the $\mathrm{Al}_{2} \mathrm{O}_{3} @$ CNTs entangled with the AlN particles (Figure 4b) reduced the sinterability of AlN, leading to a decrease in the relative density of the composite. Similar results have been reported for AlN composites reinforced with carbon nanofibers (CNFs), where the CNFs hinder the densification of the AlN ceramic matrix [28].

\subsection{Phase distribution}
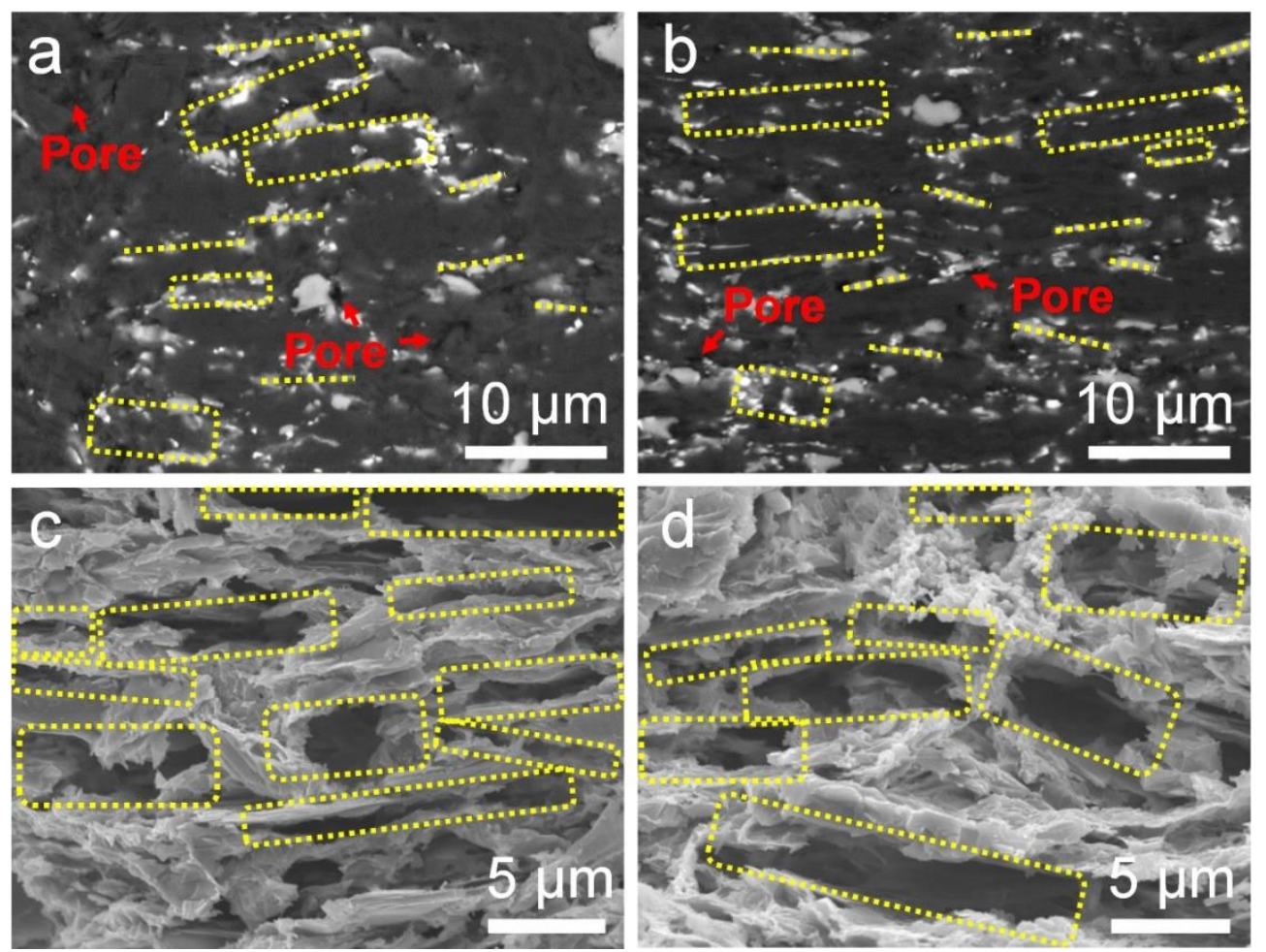

Figure 5 Polished surface microstructures (parallel to z-axial direction) of (a)

0.5CNTs-AlN/GF and (b) 2CNTs-AlN/GF; microstructures of (c) $0.5 \mathrm{CNTs}-\mathrm{AlN} / \mathrm{GF}$ and (d) 2CNTs-AIN/GF after removal graphite by decarburizing.

Figures $5 \mathrm{a}$ and $5 \mathrm{~b}$ show the backscattered electron images of the polished microstructures of $0.5 \mathrm{CNTs}-\mathrm{AlN} / \mathrm{GF}$ and $2 \mathrm{CNTs}-\mathrm{AlN} / \mathrm{GF}$, respectively. The bright areas represent the AlN phase, while the dark areas are related to the graphite phase. It 
can be seen that the AlN particles aggregated and sintered into a continuous skeleton structure. In addition, a small number of pores (highlighted by red arrows) existed in the composites. The $0.5 \mathrm{CNTs}-\mathrm{AlN} / \mathrm{GF}$ and $2 \mathrm{CNTs}-\mathrm{AlN} / \mathrm{GF}$ composites showed similar microstructures. This indicates that the $\mathrm{Al}_{2} \mathrm{O}_{3} @ \mathrm{CNT}$ concentration had negligible effect on the microstructure and phase distribution of the composites. The microstructures (in the z-axial direction) of the 0.5CNTs-AlN/GF and 2CNTs-AlN/GF composites decarburized at $975 \mathrm{~K}$ for $5 \mathrm{~h}$, are shown in Figures $5 \mathrm{c}$ and 5d, respectively. The black areas (indicated by the yellow dotted rectangle) are the holes formed by the in-situ oxidation of the GFs. Additionally, an oriented porous AlN skeleton was observed, which was similar to the skeleton shown in Figures $5 \mathrm{a}$ and $5 \mathrm{~b}$. This further confirms the $3 \mathrm{D}$ continuity of the ceramic reinforcement. The holes in Figures $5 \mathrm{c}$ and $5 \mathrm{~d}$ with a length of $\sim 15 \mu \mathrm{m}$ and a thickness of $2-5 \mu \mathrm{m}$ indicate that the structural unit of the composites had several stacked GFs.

\subsection{Mechanical properties}

The fracture toughness values of the CNTs-AlN/GF composites in the z-axial direction (loading along the z-axis) and $\mathrm{x}-\mathrm{y}$ plane (loading along the $\mathrm{x}$-axis) are shown in Figure 6a. It can be observed that the fracture toughness of the composites in the zaxial direction was higher than that in the $\mathrm{x}-\mathrm{y}$ plane. However, the fracture toughness values of the composites showed a similar variation trend. The fracture toughness of the composites increased steadily with an increase in the $\mathrm{Al}_{2} \mathrm{O}_{3} @ \mathrm{CNT}$ weight fraction up to $1 \mathrm{wt} \%$, and decreased at higher filler weight fractions. The $1 \mathrm{CNTs}-\mathrm{AlN} / \mathrm{GF}$ composite showed the maximum fracture toughness values of 1.66 and $1.40 \mathrm{MPa} \cdot \mathrm{m}^{1 / 2}$ 
in the z-axial and x-y plane directions, respectively. These values are $50 \%$ and $130 \%$ higher than the corresponding values of the AIN/GF composite. When the $\mathrm{Al}_{2} \mathrm{O}_{3} @ \mathrm{CNT}$ concentration was increased to $2 \mathrm{wt} \%$, the fracture toughness values in the two principal directions were comparable $\left(\sim 1.3 \mathrm{MPa} \cdot \mathrm{m}^{1 / 2}\right)$.
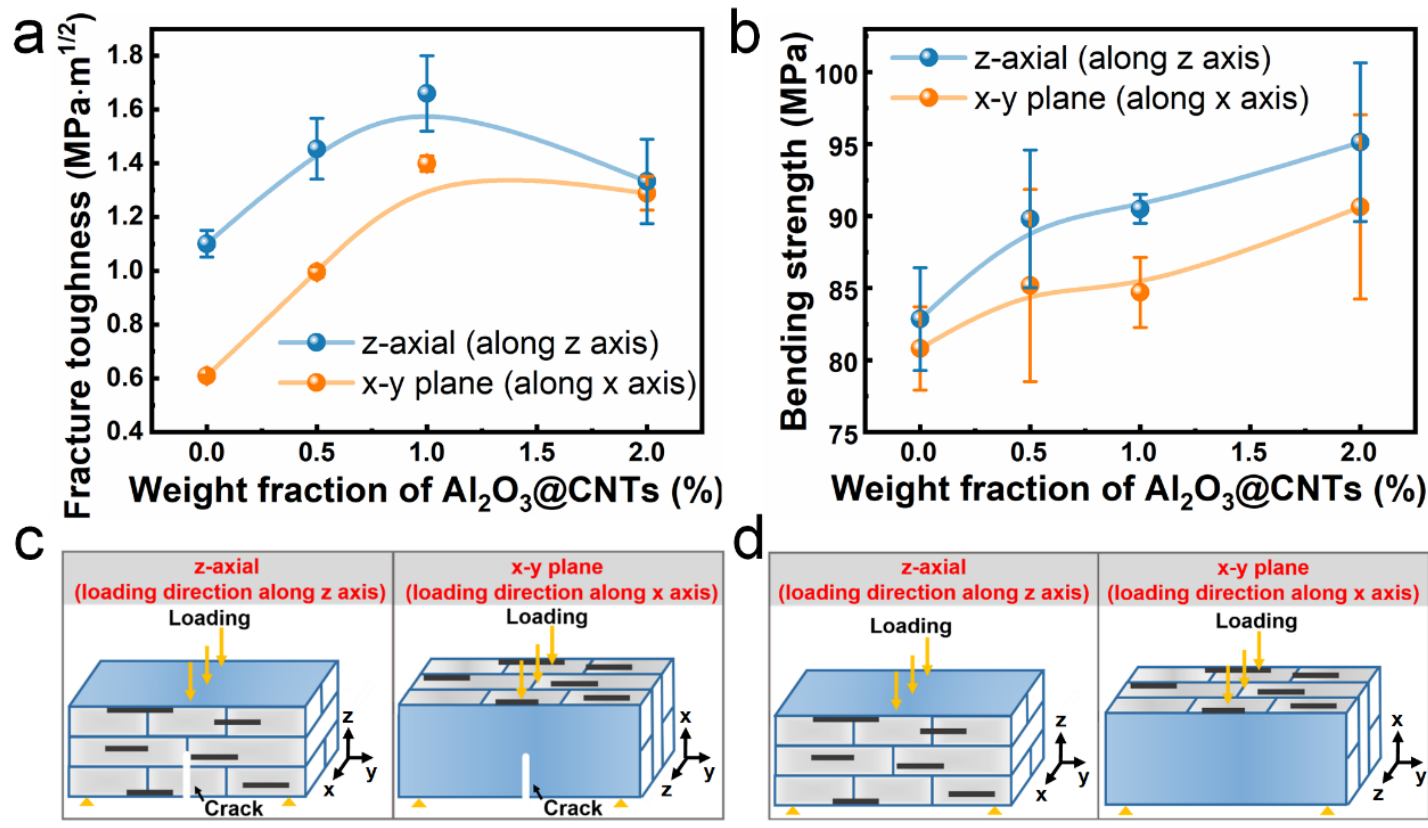

Figure 6 (a) Fracture toughness and (b) bending strength of the composites in two principle directions as a function of $\mathrm{Al}_{2} \mathrm{O}_{3} @ \mathrm{CNT}$ weight friction; the schematics of zaxial and x-y plane directions for (c) fracture toughness and (d) bending strength tests.

After the fracture toughness tests, the specimens did not cleave into two parts, but only failed. These specimens were then subjected to SEM analysis. The SEM image of the lateral surface of the samples along the z-axis (Figure 7a) showed an apparent zigzag path, where the crack front was perpendicular to the GF plane. Conversely, an almost straight crack was observed when the samples were tested along the x-y plane direction, and the crack front faced the GF edges (Figure 7b). The significant crack deflection in the z-axial direction elongated the crack propagation path as compared to 
that in the $\mathrm{x}-\mathrm{y}$ plane direction, absorbing more energy as the cracks propagated, which resulted in an increase in the toughness. The crack propagation in the CNTs-AlN/GF composites was caused by multiple toughening mechanisms, including the micro GF bridge and pull-out, nano-GF pull-out, and CNT pull-out (Figures 7c-7e). As shown in Figure 7c, some uncracked GFs bridged the crack in several microns, and some GFs pulled out at the crack faces, which inhibited the opening of the cracks and prevented or delayed catastrophic fracture [32]. Careful examination indicates that the nanoscale GFs pulled out during the crack propagation, as indicated by the white arrows in Figure $7 \mathrm{~d}$. This can be attributed to the delamination of the GFs [33]. The improvement in the toughness of the composites after the incorporation of the CNTs can mainly be attributed to the CNT pull-out effect (Figure 7e). However, it was difficult to observe the CNTs pulled out in the $x-y$ plane direction by SEM because of the shielding by the GFs. Furthermore, the rough crack plane caused by the CNT pull-out is shown in Figure 7e, as highlighted by the yellow dot ellipse. This also increased the crack-propagation resistance of the composites. In a certain range, with an increase in the CNT content, the crack plane became coarser and more energy was consumed for further crack propagation. When the $\mathrm{Al}_{2} \mathrm{O}_{3} @ \mathrm{CNT}$ weight fraction reached $2 \mathrm{wt} \%$, the improvement in the fracture toughness of the composites in the z-axial direction became insignificant because of the increase in the porosity, the reduction in the orientation degree of the GFs, and the CNT aggregation. Thus, the 1CNTs-AIN/GF composite exhibited the highest fracture toughness in both the directions. The fracture toughness of the 1CNTsAlN/GF composite in the $x-y$ plane was $25 \%$ higher than that of isotropic graphite (IG- 
110) [34], which can be attributed to the micro GF and nano-GF bridge mechanisms.
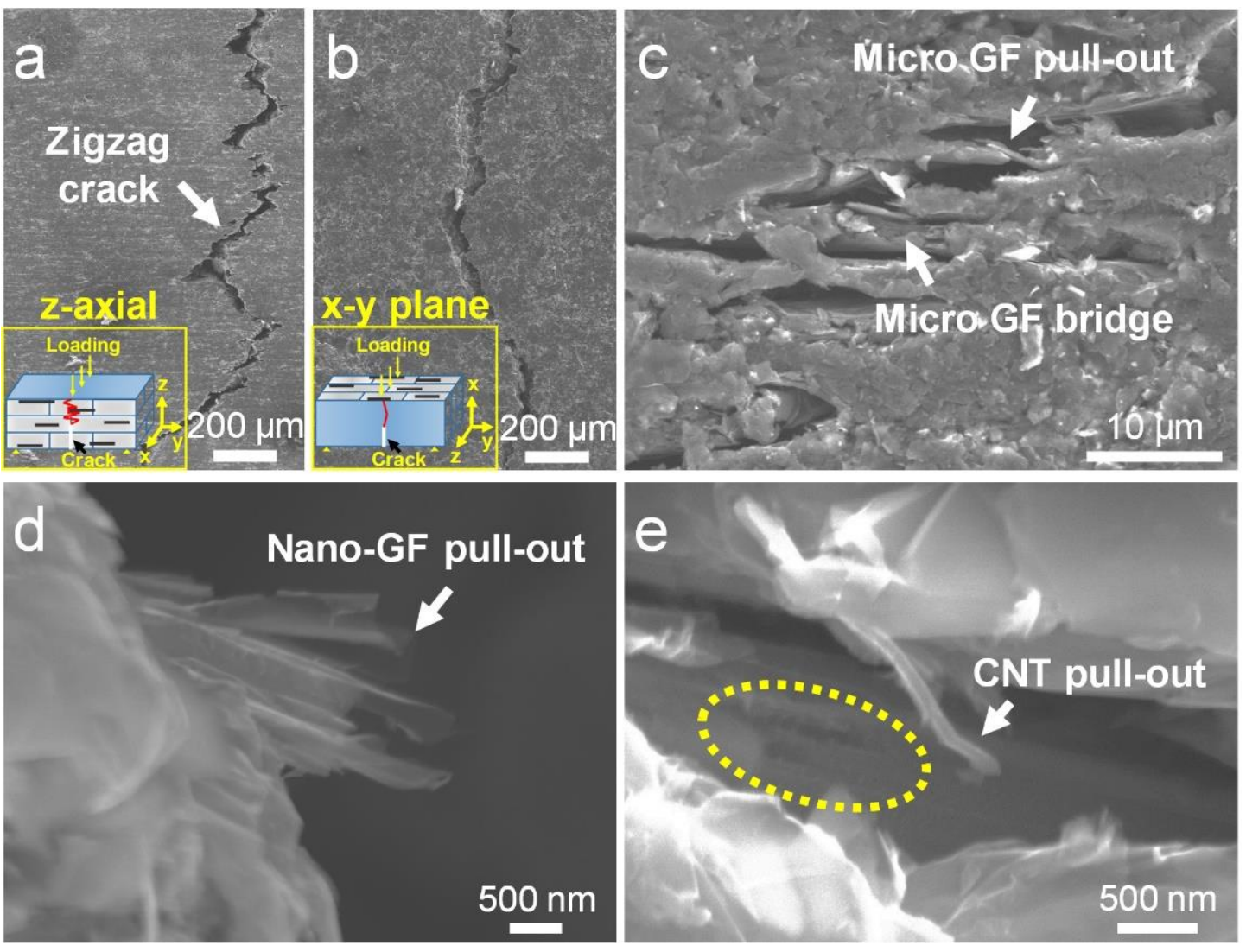

Figure 7 Crack deflection observed in (a) z-axial and (b) x-y plane directions; SEM micrographs showing (c) micro GF bridge and pull-out, (d) nano-GF pull-out and (e) CNT pull-out at the crack faces.

The bending strengths of the composites in both the z-axial (tested along the zaxis) and x-y plane (tested along x-axis) directions (Figure 6d) are shown in Figure 6b. It can be observed that the bending strength in the two principal directions increased with an increase in the $\mathrm{Al}_{2} \mathrm{O}_{3} @ \mathrm{CNT}$ concentration from 0 to $2 \mathrm{wt} \%$. The values reached 95 (z axial direction) and $89 \mathrm{MPa}$ (x-y plane direction) for the 2CNTs-AlN/GF composite, which are approximately 20 and $9 \%$ higher than those of the AlN/GF composite, respectively. The bending strength of the 1CNTs-AlN/GF composite in the 
z-axial direction was $90 \mathrm{MPa}$, which is $10 \%$ improvement over that of the AlN/GF composite.

In the AlN/GF composite, the weak GF matrix was reinforced by the AlN skeleton. During the bending tests, microcracks tended to form along the interlayer of the GFs or the GF/AlN interface owing to the stress field at the crack tip. Therefore, the maximum flaw sizes of the AIN/GF composite in the two principal directions were comparable to the lateral size of the GFs $(\sim 15 \mu \mathrm{m})$ [35]. In addition, the AlN contents of the fracture surfaces of the composite in the two principal directions were similar. Hence, the bending strengths of the AIN/GF composite in the $\mathrm{x}-\mathrm{y}$ plane and z-axial directions were comparable. After the introduction of $\mathrm{Al}_{2} \mathrm{O}_{3} @ \mathrm{CNTs}$, the fracture surface energy of the CNTs-AlN/GF composites enhanced with increasing of $\mathrm{Al}_{2} \mathrm{O}_{3} @ \mathrm{CNT}$ content, resulting in an improvement in the bending strength. It should be noted that the bending strength of the CNTs-AIN/GF composites in the z-axial direction was higher than that in the $\mathrm{x}$ $\mathrm{y}$ plane direction. When the loading direction was along the $\mathrm{z}$ axis, the CNTs were clamped effectively by the adjacent GFs, which consumed more energy in this direction during the rupture process and inevitably increased the fracture surface energy, contributing to the higher bending strength of the composites. Furthermore, the bending strength of the composites was closely related to their microstructures. The fracture surfaces of the AIN/GF and CNTs-AlN/GF composites in the two principal directions after the bending tests were characterized and are shown in Figure 8. The GFs in all the composites showed layer-by-layer stacking. The AlN/GF composite exhibited similar fracture microstructures in both the directions (Figures $8 \mathrm{a}$ and $8 \mathrm{~b}$ ). Thus, the bending 
strengths of the composite in the two principal directions were also similar. The difference in the fracture microstructures of the AlN/GF and 2CNTs-AlN/GF composites was the presence of protruding CNTs in 2CNTs-AlN/GF (Figures 8c and 8d). Most of the CNTs were located between the adjacent GFs (Figures 8e and 8f), which formed a strong bridge in the composites and thus increased the fracture surface energy of the composite.
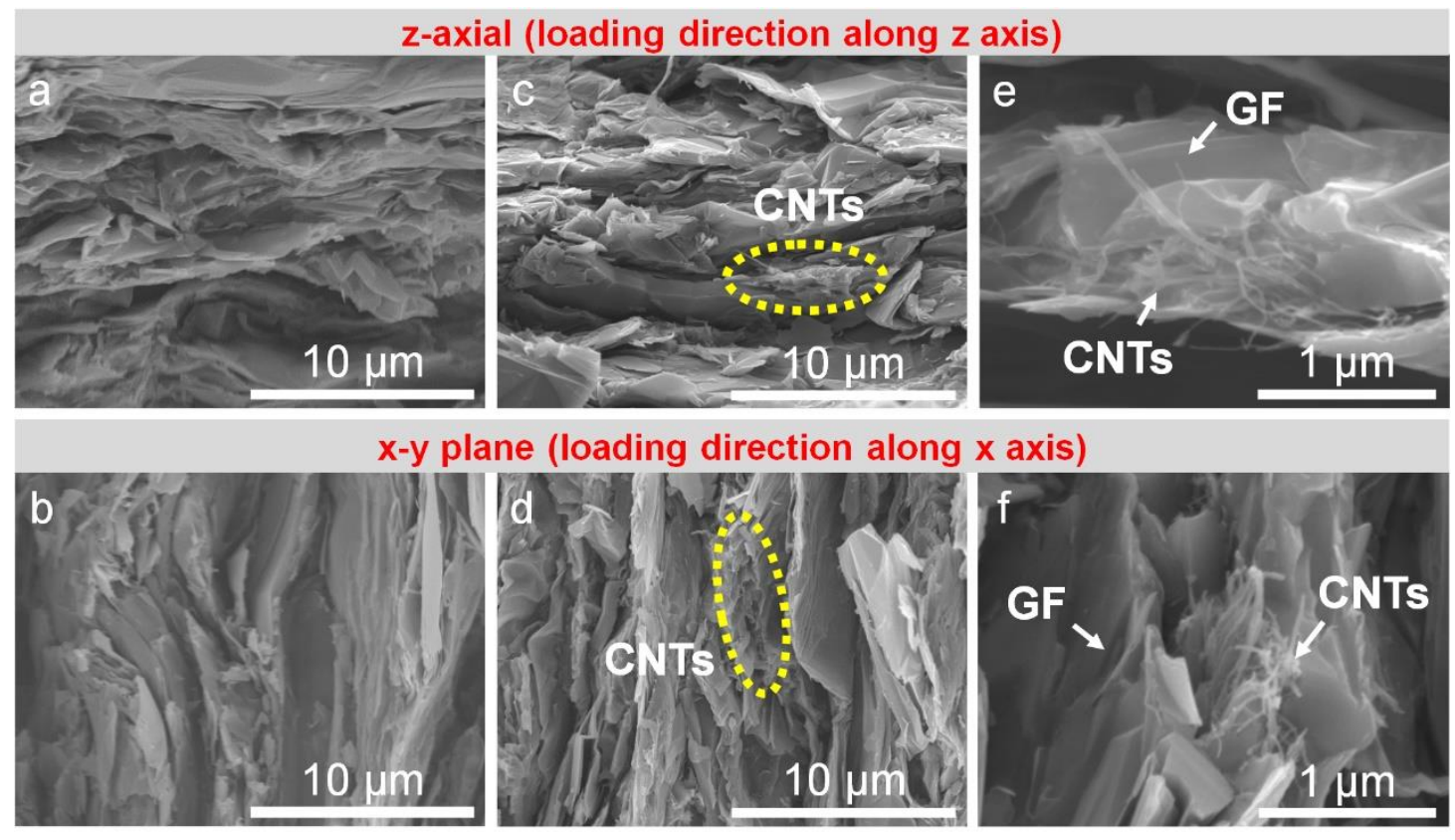

Figure 8 Fracture surfaces of (a-b) AlN/GF and (c-d) 2CNTs-AIN/GF tested along z axis and $\mathrm{x}$ axis; CNT pull-out in 2CNTs-AIN/GF along (e) $\mathrm{z}$ axis and (f) $\mathrm{x}$ axis.

\subsection{Thermophysical properties}

Figure 9a shows the TC values of the CNTs-AlN/GF composites as functions of $\mathrm{Al}_{2} \mathrm{O}_{3} @ \mathrm{CNT}$ concentration in the two principal directions. The composites exhibited an anisotropic TC. The TC values of the composites in the $\mathrm{x}-\mathrm{y}$ plane direction $(>250$ $\mathrm{W} / \mathrm{m} / \mathrm{K})$ were ten times higher than those in the $\mathrm{z}$-axial direction $(\sim 20 \mathrm{~W} / \mathrm{m} / \mathrm{K})$ because efficient heat conduction paths were formed through the alignment of highly oriented 
GFs in the x-y plane. The z-axial TC of the composites varied slightly with an increase in the $\mathrm{Al}_{2} \mathrm{O}_{3} @ \mathrm{CNT}$ concentration, which can be attributed to fact that the TC in this direction was dominated by the AlN skeleton. Owing to the higher TC of AlN ( $\sim 120$ $\mathrm{W} / \mathrm{m} / \mathrm{K})[36,37]$ than that of the GFs in the z-axial direction $(15 \mathrm{~W} / \mathrm{m} / \mathrm{K})[9]$ and the formation of the AlN skeleton in the composites, the phonons transferred mainly along the AlN skeleton in the z-axial direction. The TC in the $\mathrm{x}-\mathrm{y}$ plane exhibited an abrupt decrease from $442 \mathrm{~W} / \mathrm{m} / \mathrm{K}$ for AlN/GF to $253 \mathrm{~W} / \mathrm{m} / \mathrm{K}$ for $0.5 \mathrm{CNTs}-\mathrm{AlN} / \mathrm{GF}$ and then slightly increased to $275 \mathrm{~W} / \mathrm{m} / \mathrm{K}$ for $2 \mathrm{CNTs}-\mathrm{AlN} / \mathrm{GF}$. It is well-known that in ceramic composites, an increase in the porosity, number of interfaces, and number of defects can result in a decrease in the TC $[38,39]$. As mentioned earlier, the relative density of the composites decreased after the introduction of $\mathrm{Al}_{2} \mathrm{O}_{3} @$ CNTs. Meanwhile, the interface resistance of the composites increased after the introduction of $\mathrm{Al}_{2} \mathrm{O}_{3} @ \mathrm{CNTs}$. Moreover, the reduction in the orientation degree disturbed the two-dimensional directional heat transfer. Therefore, the TC of the AlN/GF composite decreased significantly after the addition of 0.5 wt $\% \mathrm{Al}_{2} \mathrm{O}_{3} @ \mathrm{CNTs}$. With a further increase in the $\mathrm{Al}_{2} \mathrm{O}_{3} @ \mathrm{CNT}$ weight fraction, the ultrahigh TC of the CNTs contributed to a slight improvement in the TC of the composites in the $\mathrm{x}-\mathrm{y}$ plane.

As shown in Figure 9b, the CTE value of AlN/GF in the $x-y$ plane direction was approximately $1.5 \times 10^{-6} / \mathrm{K}$, which fitted well with the value calculated by the Kerner model because of the existence of the shear effects in the composites $[13,40,41]$. With an increase in the $\mathrm{Al}_{2} \mathrm{O}_{3} @ \mathrm{CNT}$ content, the CTE of the composites remained almost constant because the intrinsic axial thermal expansion of CNTs was nearly zero [42]. 
However, an abrupt increase in the z-axial CTE from $7.3 \times 10^{-6} / \mathrm{K}$ for $\mathrm{AlN} / \mathrm{GF}$ to $15.5 \times 10^{-6} / \mathrm{K}$ for $0.5 \mathrm{CNTs}-\mathrm{AlN} / \mathrm{GF}$ was observed. The CTE remained nearly constant with a further increase in the $\mathrm{Al}_{2} \mathrm{O}_{3} @ \mathrm{CNT}$ content. The CTE of the composites was determined by the thermal expansion of the graphite matrix and the constraint of reinforcement through their interfaces in the composites [42]. In our previous study, we demonstrated that the AlN skeleton effectively restricts the z-axial CTE of graphite $\left(28 \times 10^{-6} / \mathrm{K}\right)$ to a lower value by introducing thermal stress in the AlN/GF interfaces [13]. The diameters of the CNTs were nanometers in size, which means that the CNTs have large specific surface areas. Because of the good dispersion of CNTs, a large number of GFs/CNTs/AIN interfaces can be introduced even adding a small amount of CNTs $\left(0.5 \%\right.$ for instance). It was observed that a large amount of $\mathrm{Al}_{2} \mathrm{O}_{3} @ \mathrm{CNTs}$ adhered onto the GFs (Figure 4a), which inevitably prevented the close contact between the GFs and AlN. Thus, the GF/AlN interface bonding was mechanically weakened, and the interfacial stress reduced. Furthermore, the increase in the porosity after the introduction of the CNTs also led to the release of the residual stress in the composites. The decreased residual stress was reflected by the change in the $d_{(002)}$ spacing of the graphite phase in the composites. As can be observed from the XRD patterns of the composites, the XRD peak at approximately $2 \theta=26.5^{\circ}$ (Figure 9c) corresponding to the (002) plane of graphite shifted to higher angles with an increase in the CNT content. The $d_{(002)}$ spacing of the graphite phase, as calculated using the Bragg equation, decreased with an increase in the CNT content (Figure 9d). The tensile stress $\sigma$ was calculated according to the equations [43]: 


$$
\begin{gathered}
\sigma=E \cdot \varepsilon_{d} \\
\varepsilon_{d}=\frac{d_{\mathrm{C}}-d_{\mathrm{G}}}{d_{\mathrm{G}}}
\end{gathered}
$$

where $E$ is the modulus of graphite across basal plane (36 GPa). The $\varepsilon_{d}$ represents the Z-axial strain of graphite in the composites. The $d_{\mathrm{C}}$ and $d_{\mathrm{G}}$ are the interplanar spacings of graphite in the composites and pure graphite (PDF No. 00-041-1487), respectively. It can be seen from Figure 9d that the residual stress between GFs and AlN in z-axial direction decreased from $0.99 \mathrm{GPa}$ to $0.62 \mathrm{GPa}$ with an increase in the $\mathrm{Al}_{2} \mathrm{O}_{3} @ \mathrm{CNT}$ concentration from 0 to $2 \mathrm{wt} \%$, which resulted in an insufficient constraint for the thermal expansion of GFs in z-axial direction [43]. Thus, the CTE of the composites increased in z-axial direction.
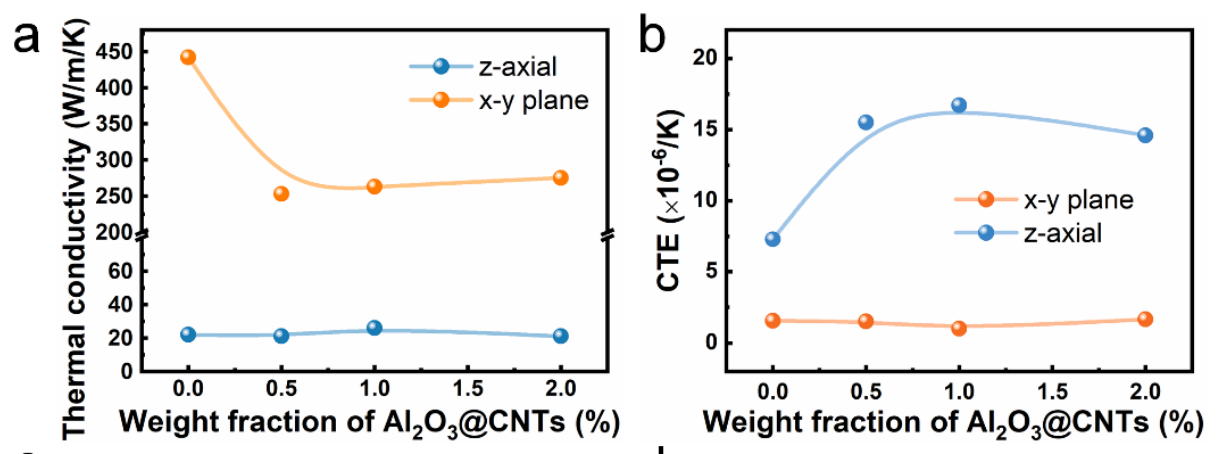

$\mathrm{C}$
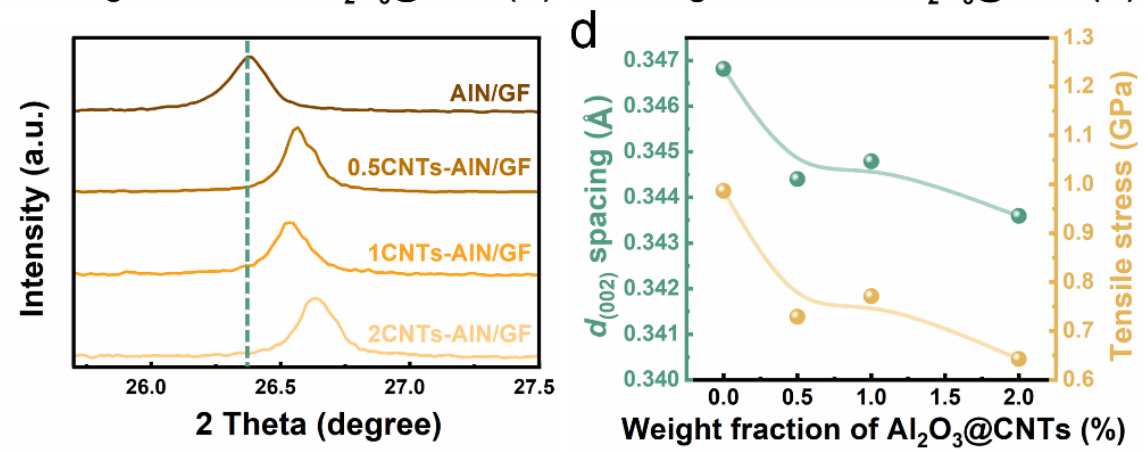

Figure 9 (a) TC and (b) CTE values of CNTs-AIN/GF composites in x-y plane and zaxial directions as a function of $\mathrm{Al}_{2} \mathrm{O}_{3} @$ CNTs concentration; (c) XRD patterns at about $2 \theta=26.5^{\circ}$ and (d) $d_{(002)}$ spacings and stress of graphite phase in CNTs-AlN/GF composites. 


\section{Conclusions}

In summary, highly orientated $\mathrm{Al}_{2} \mathrm{O}_{3} @$ CNTs-reinforced AlN/GF composites were prepared using vacuum infiltration followed by SPS for application as TMMs. The main findings are summarized as follows.

(1) All the composites had good orientation (Lotgering factor $f>95 \%$ ). The addition of $\mathrm{Al}_{2} \mathrm{O}_{3} @$ CNTs slightly decreased the orientation degree of the GFs and the relative density of the composites.

(2) The good fracture toughness of the CNTs-AlN/GF composites was due to the combined effect of multiple toughening mechanisms, including the micro-GF bridge and pull-out, nano-GF pull-out, and CNT pull-out. The bending strength of the composites also improved with an increase in the $\mathrm{Al}_{2} \mathrm{O}_{3} @ \mathrm{CNT}$ weight fraction, which can be attributed to the increased fracture surface energy of the composites by the welldispersed CNTs.

(3) The 1CNTs-AlN/GF composite possessed optimal comprehensive mechanical properties. The composite showed a maximum fracture toughness value of 1.66 $\mathrm{MPa} \cdot \mathrm{m}^{1 / 2}$ and a bending strength of $90 \mathrm{MPa}$, which are 50 and $10 \%$ higher than those of the AlN/GF composite, respectively.

(4) After the introduction of the CNTs, the TC of the composites in the x-y plane decreased from 442 to $253-275 \mathrm{~W} / \mathrm{m} / \mathrm{K}$, whereas the $\mathrm{z}$-axial CTE increased to $\sim 15.5 \times 10^{-6} / \mathrm{K}$ owing to the insufficient constraint for thermal expansion of the GFs in the $\mathrm{z}$-axial direction.

\section{Acknowledgements}


This work was supported by the National Natural Science Foundation of China

(No. 51872222, 92163112), the Shaanxi Innovation Capacity Support Program

(2018TD-031) and the Innovative Scientific Program of CNNC.

\section{References}

[1] Z. Wei, W. Xie, B. Ge, Z. Zhang, W. Yang, H. Xia, B. Wang, H. Jin, N. Gao, Z. Shi, Enhanced thermal conductivity of epoxy composites by constructing aluminum nitride honeycomb reinforcements, Compos. Sci. Technol. 199 (2020) 108304.

[2] A.L. Moore, L. Shi, Emerging challenges and materials for thermal management of electronics, Mater. Today. 17 (2014) 163-174.

[3] Z. Zhang, B. Ge, W. Xie, Z. Wei, W. Yang, Y. Li, Z. Shi, Effect of Si alloying content on the microstructure and thermophysical properties of $\mathrm{SiC}$ honeycomb/Al-Mg-Si composites prepared by spontaneous infiltration, Ceram. Int. 46 (2020) 10934-10941.

[4] Z. Wei, W. Xie, X. Zhang, Z. Zhang, Y. Li, H. Xia, B. Wang, Z. Shi, Preparation of AlN microhoneycombs with high permeability via freeze-casting, J. Eur. Ceram. Soc. 40 (2020) 4462-4468.

[5] J.M. Molina, J. Narciso, L. Weber, A. Mortensen, E. Louis, Thermal conductivity of Al-SiC composites with monomodal and bimodal particle size distribution, Mater. Sci. Eng. A. 480 (2008) 483-488.

[6] G. Yuan, X. Li, Z. Dong, A. Westwood, Z. Cui, Y. Cong, H. Du, F. Kang, Graphite blocks with preferred orientation and high thermal conductivity, Carbon 50 (2012) 175-182.

[7] Z. Liu, Q. Guo, J. Shi, G. Zhai, L. Liu, Graphite blocks with high thermal conductivity derived from natural graphite flake, Carbon 46 (2008) 414-421.

[8] W. Li, Y. Liu, G. Wu, Preparation of graphite flakes/Al with preferred orientation and high thermal conductivity by squeeze casting, Carbon 95 (2015) 545-551.

[9] I. Firkowska, A. Boden, B. Boerner, S. Reich, The origin of high thermal conductivity and ultralow thermal expansion in copper-graphite composites, Nano Lett. 15 (2015) 4745-4751.

[10] S. Ren, J. Chen, X. He, X. Qu, Effect of matrix-alloying-element chromium on the microstructure and properties of graphite flakes/copper composites fabricated by hot pressing sintering, Carbon 127 (2018) 412-423.

[11] X. Fang, L. Jiang, L. Pan, S. Yin, T. Qiu, J. Yang, High-thermally conductive AlN-based microwave attenuating composite ceramics with spherical graphite as attenuating agent, J. Adv. Ceram. 10 (2021) 301-319.

[12] X. Wang, Y. Su, Q. Ouyang, C. Zhu, H. Cao, D. Zhang, Fabrication, mechanical and thermal properties of copper coated graphite films reinforced copper matrix laminated composites via ultrasonic-assisted electroless plating and vacuum hot-pressing sintering, Mater. Sci. Eng. A. 824 (2021) 141768.

[13] X. Zhang, Z. Shi, X. Zhang, K. Wang, Y. Zhao, H. Xia, J. Wang, Three dimensional AlN skeleton-reinforced highly oriented graphite flake composites with excellent mechanical and thermophysical properties, Carbon 131 (2018) 94-101.

[14] G. Yuan, X. Li, Z. Dong, X. Xiong, B. Rand, Z. Cui, Y. Cong, J. Zhang, Y. Li, Z. Zhang, J. Wang, Pitch-based ribbon-shaped carbon-fiber-reinforced one-dimensional carbon/carbon 
composites with ultrahigh thermal conductivity, Carbon 68 (2014) 413-425.

[15] Y. Zhao, Z. Liu, H. Wang, J. Shi, J. Zhang, Z. Tao, Q. Guo, L. Liu, Microstructure and thermal/mechanical properties of short carbon fiber-reinforced natural graphite flake composites with mesophase pitch as the binder, Carbon 53 (2013) 313-320.

[16] J. Qin, C. Wang, Z. Yao, Z. Ma, X. Cui, Q. Gao, Y. Wang, Q. Wang, H. Wei, Mechanical property deterioration and defect repair factors of carbon fibers during the continuous growth of carbon nanotubes by chemical vapor deposition, Ceram. Int. 47 (2021) 19213-19219.

[17] S.T. Huxtable, D.G. Cahill, S. Shenogin, L. Xue, R. Ozisik, P. Barone, M. Usrey, M.S. Strano, G. Siddons, M. Shim, P. Keblinski, Interfacial heat flow in carbon nanotube suspensions, Nat. Mater. 2 (2003) 731-734.

[18] A.J. Kessman, J. Zhang, S. Vasudevan, J. Lou, B.W. Sheldon, Carbon nanotube pullout, interfacial properties, and toughening in ceramic nanocomposites: mechanistic insights from single fiber pullout analysis, Adv. Mater. Interfaces. 2 (2015) 1-10.

[19] Y. Zhao, J. Shi, H. Wang, Z. Tao, Z. Liu, Q. Guo, L. Liu, A sandwich structure graphite block with excellent thermal and mechanical properties reinforced by in-situ grown carbon nanotubes, Carbon 51 (2013) 427-430.

[20] D. He, M. Bozlar, Diameter- and length-dependent self-organizations of multi-walled carbon nanotubes on spherical alumina microparticles, Carbon 48 (2009) 1159-1170.

[21] M. Bozlar, D. He, J. Bai, Y. Chalopin, N. Mingo, S. Volz, Carbon nanotube microarchitectures for enhanced thermal conduction at ultralow mass fraction in polymer composites, Adv. Mater. 22 (2010) 1654-1658.

[22] W. Li, D. He, Z. Dang, J. Bai, In situ damage sensing in the glass fabric reinforced epoxy composites containing CNT- $\mathrm{Al}_{2} \mathrm{O}_{3}$ hybrids, Compos. Sci. Technol. 99 (2014) 8-14.

[23] S.W. Jung, S.Y. Kim, H.W. Nam, K.S. Han, Measurements of fiber orientation and elasticmodulus analysis in short-fiber-reinforced composites, Compos. Sci. Technol. 61 (2001) 107116.

[24] W. Feng, M. Qin, P. Lv, J. Li, Y. Feng, A three-dimensional nanostructure of graphite intercalated by carbon nanotubes with high cross-plane thermal conductivity and bending strength, Carbon 77 (2014) 1054-1064.

[25] M. Qin, Y. Feng, T. Ji, W. Feng, Enhancement of cross-plane thermal conductivity and mechanical strength via vertical aligned carbon nanotube@graphite architecture, Carbon 104 (2016) 157-168.

[26] Y. Huang, C. Wan, Controllable fabrication and multifunctional applications of graphene/ceramic composites, J. Adv. Ceram. 9 (2020) 271-291.

[27] Y. Zhang, H. Han, N. Wang, P. Zhang, Y. Fu, M. Murugesan, M. Edwards, K. Jeppson, S. Volz, J. Liu, Improved heat spreading performance of functionalized graphene in microelectronic device application, Adv. Funct. Mater. 25 (2015) 4430-4435.

[28] Z. Shi, S. Chen, J. Wang, G. Qiao, Z. Jin, Mechanical and electrical properties of carbon nanofibers reinforced aluminum nitride composites prepared by plasma activated sintering, J. Eur. Ceram. Soc. 31 (2011) 2137-2143.

[29] T. Okuni, Y. Miyamoto, H. Abe, M. Naito, Joining of silicon carbide and graphite by spark plasma sintering, Ceram. Int. 40 (2014) 1359-1363.

[30] J.L. Jones, E.B. Slamovich, K.J. Bowman, Critical evaluation of the Lotgering degree of orientation texture indicator, J. Mater. Res. 19 (2004) 3414-3422. 
[31] K. Shen, Q. Zhang, Z. Huang, J. Yang, G. Yang, W. Shen, F. Kang, Interface enhancement of carbon nanotube/mesocarbon microbead isotropic composites, Compos. Part A Appl. Sci. Manuf. 56 (2014) 44-50.

[32] C. Sun, Y. Huang, Q. Shen, W. Wang, W. Pan, P. Zong, L. Yang, Y. Xing, C. Wan, Embedding two-dimensional graphene array in ceramic matrix, Sci. Adv. 6 (2020) 1-13.

[33] D. Jiao, J. Zhang, Y. Liu, X. Liu, Q. Zhang, S. Tang, Z. Liu, Z. Zhang, Hierarchical toughening of bioinspired nacre-like hybrid carbon composite, Carbon 171 (2021) 409-416.

[34] T. Yamada, Y. Matsushima, M. Kuroda, J. Sumita, T. Shibata, I. Fujita, K. Sawa, Evaluation of fracture toughness of fine-grained isotropic graphites for HTGR, Nucl. Eng. Des. 271 (2014) 323-326.

[35] X. Zhou, L. Jing, Y.D. Kwon, J.Y. Kim, Z. Huang, D.H. Yoon, J. Lee, Q. Huang, Fabrication of $\mathrm{SiCw} / \mathrm{Ti}_{3} \mathrm{SiC}_{2}$ composites with improved thermal conductivity and mechanical properties using spark plasma sintering, J. Adv. Ceram. 9 (2020) 462-470.

[36] Z. Wei, K. Li, B. Ge, C. Guo, H. Xia, Y. Guo, Z. Shi, Synthesis of nearly spherical AlN particles by an in-situ nitriding combustion route, J. Adv. Ceram. 10 (2021) 291-300.

[37] S. Baskut, A. Cinar, S. Turan, Directional properties and microstructures of spark plasma sintered aluminum nitride containing graphene platelets, J. Eur. Ceram. Soc. 37 (2017) 3759-3772.

[38] Z. Wei, Z. Zhang, X. Zhang, Z. Li, T. Li, J. Hu, S. Xu, Z. Shi, Preparation of unidirectional porous AlN ceramics via the combination of freeze casting and combustion synthesis, J. Mater. Sci. Technol. 100 (2022) 161-168.

[39] W. Chen, Y. Miyamoto, T. Tojo, M. Naito, Densification and properties of AlN ceramic bonded carbon, J. Eur. Ceram. Soc. 32 (2012) 245-250.

[40] E.H. Kerner, The Elastic and thermo-elastic properties of composite media, Proc. Phys. Soc. Sect. B. 69 (1956) 808-813.

[41] J. Li, H. Zhang, L. Wang, Z. Che, Y. Zhang, J. Wang, M.J. Kim, X. Wang, Optimized thermal properties in diamond particles reinforced copper-titanium matrix composites produced by gas pressure infiltration, Compos. Part A Appl. Sci. Manuf. 91 (2016) 189-194.

[42] Z. Liu, B.L. Xiao, W. Wang, Z. Ma, Elevated temperature tensile properties and thermal expansion of CNT/2009Al composites, Compos. Sci. Technol. 72 (2012) 1826-1833.

[43] W. Qi, Z. He, H. Tang, B. Zhang, C. Zhang, L. Gao, H. Xia, J. Wang, P. Huai, X. Zhou, J. Song, D. Zhang, X. Wang, X. Du, G. Lei, H. Xia, J. Wang, P. Huai, X. Zhou, Effects of FLiNaK infiltration on thermal expansion behavior of graphite, J. Mater. Sci. 52 (2017) 4621-4634. 